\title{
Systemic Sclerosis and Malignancy: A Review of Current Data
}

\author{
Nabil Zeineddine ${ }^{\mathrm{a}, \mathrm{b}}$, Lara El Khoury ${ }^{\mathrm{a}}$, Joseph Mosak ${ }^{\mathrm{a}}$
}

\begin{abstract}
Systemic sclerosis (SSc) is associated with increased risk of malignancy. The organ systems most commonly affected are the lungs, the breasts and the hematological system. Risk factors predisposing a SSc patient for development of malignancy are not well defined, and the pathogenic basis of the association is yet to be explained. The incidence of malignancies in SSc patients is variable from one report to another, but most importantly, questions regarding the role of immunosuppressive therapies and the effect of autoantibodies have weak or sometimes contradictory answers in most of the currently available literature and physicians have no available guidelines to screen their SSc patients for malignancies. The lack of a concretely defined high-risk profile and the absence of malignancy screening guidelines tailored for SSc patients raise the importance of the need for more studies on the association of SSc and cancer and should incite rheumatology colleges to develop specific recommendations for the clinician to follow while approaching patients with SSc.
\end{abstract}

Keywords: Systemic sclerosis; Malignancy; Fibrosis; Immunosuppression

\section{Introduction}

Scleroderma is an autoimmune disease (AD) causing sclerosis and thickening of the skin. It can manifest as a localized disorder, such as in linear scleroderma or in morphea, or as a systemic condition in which case it is identified as "systemic sclerosis" (SSc).

SSc comprises multiple subsets: diffuse cutaneous SSc, limited cutaneous SSc, SSc sine scleroderma (where only internal organs are involved) and environmentally induced scleroderma (following exposure to vinyl chloride, pesticides or

Manuscript accepted for publication June 24, 2016

${ }^{a}$ Northwell Health at Staten Island University Hospital, 475 Seaview Avenue, Staten Island, NY 10305, USA

${ }^{b}$ Corresponding Author: Nabil Zeineddine, Northwell Health at Staten Island University Hospital, 475 Seaview Avenue, Staten Island, NY 10305, USA. Email: nzeineddine@northwell.edu

doi: http://dx.doi.org/10.14740/jocmr2606w other agents that can precipitate scleroderma).

In addition to the skin and vascular injuries seen in SSc, the disease frequently includes internal organ involvement that can affect the patient's prognosis and quality of life. Gastrointestinal (GI) involvement can include esophagitis, reflux, GI bleed, "watermelon stomach", bacterial overgrowth and malabsorption. Renal involvement through scleroderma renal crisis (SRC) manifests with acute onset of kidney failure and abrupt onset of hypertension and microangiopathy. The two organs, whose involvement is associated with the worst repercussions and dreaded complications, remain the lungs, through interstitial lung disease (ILD) and pulmonary artery hypertension $(\mathrm{PAH})$, and the heart through heart failure and arrhythmias.

Several reports have also demonstrated an increased risk of malignancy in patients with SSc. However, this risk has rarely been the major concern for either the clinician or the patient, as the highest mortality in SSc patients is due to cardiac disease and pulmonary fibrosis. With the emergence of organ-based treatment, especially ACE inhibitors for renal crisis, and device-based treatment for heart failure, the mortality from kidney and cardiac damage has decreased significantly. As a result, the increased risk of cancer in SSc has become a stronger concern for both the physician and the patient.

Recently, the American College of Rheumatology (ACR) updated its classification criteria for $\mathrm{SSc}$ with the intent to classify more cases at an earlier stage and thus, avoid disease progression [1].

This new classification, in parallel with the above innovations in the disease treatment, will give the physician and the patient a new perception of the disease, and will deepen the discussion about association of SSc with malignancies.

This association is remarkably important due to the lack of malignancy screening guidelines tailored for SSc patients (in contrast to PAH [2], and other SSc organ damage [3]) and the lack of a concretely defined high risk disease profile.

\section{Association of SSc With Malignancy}

\section{Pathophysiology of the association}

The incidence of malignant tumors was shown to be elevated in SSc patients [4]. Recently, with the reduction in mortality of SSc related to renal crisis and lung fibrosis, experts and pa- 
tients have been more concerned about long-term morbidities of SSc, especially the malignancies that might be associated with this rheumatologic condition.

In this part of our review, we will focus on the risk factors for developing malignancies in SSc and the pathogenic basis of this association.

Patients of an older age at scleroderma onset [5] and with the diffuse cutaneous subtype were shown to be at higher risk of malignancy [6].

Review of the current literature reveals conflicting results regarding gender-related malignancy risk. In a large metaanalysis, the risk of malignancy in SSc was found to be significantly higher in males [7]. On the other hand, several reviews have concluded that female gender confers a higher risk of developing cancer in SSc patients [6]. Other reviews on the epidemiology of SSc and malignancy showed that male gender confers a higher risk through exposure to silica dust, than male gender related risk by itself [8].

In a large cohort study, the gender-specific standardized incidence ratio (SIR) was found to be 2.2 for men $(95 \% \mathrm{CI}$ : $1.7-2.8)$ and 1.3 for women (95\% CI: 1.1 - 1.6), indicating that men with SSc are at a higher increased risk for cancer compared to women [4].

In addition to gender and age, current data focus on the pathogenic basis of the association between $\mathrm{SSc}$ and malignancy.

The roles of fibrosis, chronic inflammation and B-cell stimulation have been studied as the backbones of this association. Many available data suggest important contributions by a number of autoantibodies, genetics, environmental triggers and DNA oxidative damage that are present in both diseases.

Immunosuppressive therapy used in SSc and in cancer provides another convincing explanation of the association.

\section{Role of fibrosis}

Data relating fibrosis to the development of cancer in SSc have been inconclusive. While some studies have found that pulmonary fibrosis does not increase the risk of lung cancer [9], others concluded that chronic inflammation and repair related to the nature of SSc disease may represent one of the mechanisms for the development of lung cancer and esophageal adenocarcinoma (EAC) in the context of pulmonary fibrosis and esophageal damage by longstanding reflux disease [10].

The scarring of pulmonary tissue can block the lymphatic channels and lead to accumulation of carcinogens. These carcinogens participate in the transformation of hyperplastic epithelium initially to metaplasia, then to neoplasia. Through this process, fibrotic tissue might be the nidus of cancer in $\mathrm{SSc}$ patients [11].

\section{Role of autoantibodies}

There is no clearly established correlation to date between malignancy in SSc and autoantibodies, but it is generally known that the relationship between cancer and autoimmunity is complex and bidirectional. In SSc, autoantibodies with the highest titer are the most strongly associated with the clinical phenotype. Many studies have found an association between the diagnosis of SSc and malignancy with specific antibodies, most commonly anti-RNA polymerase III [12-14].

Despite the large available data supporting the correlation between positive anti-RNA polymerase III antibodies in scleroderma and malignancy [15], some studies show similar prevalence of cancer in scleroderma patients with positive or negative RNA polymerase III antibodies [16]: in one study, for example, anti-RNA polymerase III positive Australian patients had 4.2-fold increased odds of having malignancy diagnosed within 5 years of scleroderma onset compared to patients negative for this antibody, but the overall prevalence of cancer was similar between those with or without RNA polymerase III antibody [12]. In another prospective case control study conducted on patients with cancer diagnosed within 3 years of SSc onset, $55.3 \%$ were RNA polymerase positive while only $13.6 \%$ were positive for anti-topoisomerase 1 and $22 \%$ positive for anti-centromere [13]. Anti-RNA polymerase III positivity was a marker of malignancy synchronous to the onset of SSc in a cohort of 466 Italian SSc patients [17], but this link was rejected in a study that showed that only antitopoisomerase I positivity confers a short cancer-scleroderma interval [5].

Many studies suggested that malignancy may initiate the scleroderma-specific immune response and drive disease in a subgroup of scleroderma patients [14].

In conclusion, despite the absence of a clearly established correlation with autoantibodies, the onset of scleroderma in an older patient, especially when severe and with high autoantibodies titers, should trigger the clinician to perform age-appropriate cancer screening, particularly if the patient manifests signs and symptoms of both conditions.

\section{Role of immunotherapy}

Immunosuppressive therapy, in particular cyclophosphamide, remains the main treatment for progressive skin involvement and active ILD. Mycophenolate mofetil (MMF) is a promising alternative to cyclophosphamide. T-cell (sirolimus and alefacept) and B-cell (rituximab (RTX))-targeted therapies have provided encouraging results in some studies for the treatment of SSc as well. These immunosuppressive agents might play a role in development of malignancy in patients with SSc.

Cyclophosphamide is an established bladder carcinogen [18]. The risk is dose-dependent [19], and requires an induction time [20]. In a double-blind randomized placebo controlled trial, oral cyclophosphamide was found to be beneficial in the treatment of SSc with a favorable risk-benefit ratio, but serious adverse events were documented and labeled to be possibly related to the drug, including squamous cell carcinoma, angiosarcoma and carcinoma in situ of the bladder [21]. Studies also noted a higher rate of hematological and lymphoreticular malignancies with cyclophosphamide therapy [20].

Mycophenolate has also been questioned as a risk factor for malignancy in patients with scleroderma. Some reports suggest cause and effect relationship between treatment of SSc patients with mycophenolate and development of cancer, with 
Table 1. Lung Cancer and SSc: Summary of Four Major Studies

\begin{tabular}{|llll}
\hline & SIR & $\begin{array}{l}\text { Number of } \\
\text { patients }\end{array}$ & $\begin{array}{l}\text { Years of } \\
\text { follow-up }\end{array}$ \\
\hline Kuo et al [25] & 4.2 & 2,053 & $1996-2008$ \\
\hline Hill et al [26] & 5.9 & 441 & $1993-2000$ \\
\hline Rosenthal et al [27] & 4.9 & 917 & $1965-1983$ \\
Chatterjee et al [28] & 1.23 & 538 & $1973-2004$ \\
\hline
\end{tabular}

regression of the cancer after removal of the MMF [22].

The rationale for the use of RTX in SSc is based on experimental evidence indicating that B cells may be actively involved in the fibrotic process [23]. In humans, B-cell infiltration is a prominent finding in lung biopsies of patients with SSc-associated ILD [24]. Clinical data regarding the use of RTX in SSc are so far encouraging. Rarely, the development of aplastic anemia and Waldenstrom macroglobulinemia has been attributed to RTX, but the development of malignancy with RTX has not yet been reported.

Immunosuppressive therapy controls active ILD in SSc patients and limits progression of fibrosis. As mentioned above, fibrosis plays a major role in the accumulation of oxidants and development of cancer. On the other hand, some immunosuppressive agents are known to have a carcinogenic effect. Based on this, and with the lack of conclusive, large studies, the riskbenefit ratio of immunosuppressive therapy should be assessed in each patient individually, and explained thoroughly to the patient prior to the initiation of treatment.

\section{Incidence of malignancy by organ system}

\section{Lung cancer}

Lung cancer is one of the few neoplasms for which the association with $\mathrm{SSc}$ is well reported in the literature (Table 1 [25-28]).

The basis of this association resides in the roles of lung fibrosis, chronic inflammatory state and immunosuppressive therapy in the initiation of the malignant process. On the other hand, scleroderma may represent a paraneoplastic process occurring as a consequence of the ongoing malignancy.

The observed incidence of lung cancer in SSc patients was reported to be as high as $5 \%$ in an Italian cohort study (odds ratio (OR) of 2.6 in males and 5.6 in females) [29]. In the same study, the risk of developing lung cancer increased significantly in patients diagnosed with SSc at younger age $(42.3 \pm 15.4 \mathrm{SD}$ vs. $51.9 \pm 14.2 \mathrm{SD}$ years), those positive for anti-Scl-70 antibodies (OR: 6.4), and those with evidence of lung fibrosis (OR: 6.7 for patients with $\mathrm{FVC}<75 \%$ ).

In one of the largest studies on SSc and malignancy, Kuo et al reported 1\% incidence of lung cancer in 2,053 Taiwanese SSc patients who were followed from 1996 to 2008 [25]. In this registry-based study, SSc patients had a 4.2-fold risk of developing lung cancer compared to their counterparts in the general population.

This finding is comparable to an SIR of 5 in an Australian study [26] and SIR of 4.9 in a Swedish study [27].

Contrary to the abovementioned studies, a large registrybased cohort from Detroit, USA, did not find statistical evidence of an increased incidence of lung cancer (or malignancy in general, except liver cancer) in SSc patients. Researchers attributed their finding to the high background rate of lung cancer in the metropolitan Detroit area [28].

In summary, young age at disease onset, the presence of ILD [30, 31], and female gender [32] are believed to confer higher risk of developing lung malignancy in patients with SSc. The relative risk of lung cancer in smokers (varying from 10 to 30-fold) might still be higher than in those high risk SSc patients, but for smokers, guidelines suggesting annual low dose helical CT chest already exist. The need remains for guidelines regarding lung cancer screening in SSc patients.

\section{Breast cancer}

Many authors have described an increased risk of breast cancer in patients with SSc [33, 34], but only few studies have suggested a possible causal relationship between the two [31, 35].

A population-based review of 318 patients with SSc by Colaci et al [36] during a period of 10 years revealed a significantly higher incidence of breast cancer in these patients. These results were not related to the clinical or serological characteristics of the studied population, smoking status, total $\mathrm{X}$-ray exposure, or the use of cyclophosphamide.

Moreover, some data $[37,38]$ have suggested an increased risk of breast cancer with the use of calcium channel blockers (CCBs). In fact, a large population-based case-control study [39] showed that prolonged use of CCBs for more than 10 years correlates with a higher risk of both ductal and lobular breast cancers (OR: 2.6, 95\% CI: p 0.04 and OR: $2.6,95 \%$ CI: p 0.01 , respectively). This hypothesized association between the use of CCBs and breast cancer can be partially explained by the role of calcium in cell apoptosis, such as activation of the caspase pathway, induction of endonuclease activity and mitochondrial permeation. By modifying the intracellular calcium level, CCBs can indirectly affect these regulatory pathways, impairing cell apoptosis and thus promoting the development of malignancies [40].

On the same note, Colaci et al [36] found that the development of breast cancer was primarily reported in patients with limited SSc, in which Raynaud's phenomenon is a long-term manifestation. Assuming that these patients were receiving a long-term course of CCBs makes this therapy a possible confounding variable that might explain the increased risk of breast cancer associated with SSc.

In an exploratory study, Derk [41] compared patients with SSc who developed breast cancer to those who did not. Further analysis compared patients who developed breast cancer before the diagnosis of SSc to those diagnosed after. A lack of ANA positivity, an older age at diagnosis of $\mathrm{SSc}$, as well as the presence of pulmonary fibrosis were more common in patients with $\mathrm{SSc}$ who have been diagnosed with breast cancer. 
Table 2. Breast Cancer and SSc: Proposed Risk Factors

\begin{tabular}{ll}
\hline Prolonged use of CCBs (> 10 years) & Li et al [37, 39] \\
& $\begin{array}{l}\text { Fitzpatrick et al [38] } \\
\text { Daling [40] }\end{array}$ \\
$\begin{array}{l}\text { Increased collagen deposition } \\
\begin{array}{l}\text { Hormonal influence (increased } \\
\text { prolactin and DHEA) }\end{array}\end{array}$ & Martin and Boyd [42] \\
CAV1 regulated TGF/Smad pathway & Qian and Ueno [44] \\
\hline
\end{tabular}

It has also been reported that the increase in mammographic densities such as those caused by the increased collagen deposition seen in SSc, is an important risk factor for the development of breast cancer [42].

SSc and breast cancer appear to be epidemiologically linked, and hormonal variations can explain why these two conditions are more commonly seen in women. In fact, elevated levels of prolactin and dehydroepiandrosterone have been seen in both patients with SSc and in breast cancer patients. Furthermore, a retrospective study done by Artlett et al [43] showed that nulliparous women with SSc had an earlier onset of the disease and a higher mortality due to SSc.

The Cav-1 regulated TGF/Smad pathway plays a role in the pathogenesis of both breast cancer as well as tissue fibrosis in SSc. In their report, Qian and Ueno [44] proposed that this pathway can partially explain the link between breast cancer and SSc.

In summary, there is a considerable amount of data suggesting an increased incidence of breast cancer in patients with SSc [37-40, 42-44] (Table 2), but the evidence remains weak. Furthermore, several studies have failed to show an increased frequency of breast cancer associated with SSc [28, 30], and this variability is believed to be related to differences in study design.

This controversy suggests that additional screening for breast cancer in SSc patients might be necessary only in highrisk patients.

\section{Lymphoma}

1) Non-Hodgkin lymphoma (NHL)

An association between ADs and the development of NHL has been described in several previous studies [45-47]. A population-based study of nearly 25,000 NHL patients performed in Denmark and Sweden [45] found that a personal history of ADs (including SSc) was linked to NHL with an OR from 1.6 to 5.4. Another large-scale Swedish study [48] involving 878,161 patients diagnosed with ADs over 9 years, revealed that, out of the 33 studied ADs, 21 showed markedly increased risk of NHL, with an SIR of 2.1 for SSc.

It has been suggested that the interplay between multiple factors such as the chronic autoimmune stimulation in ADs, the immunotherapy used in these diseases, as well as some shared genetic and environmental factors [49], might explain the development of NHL complicating the course of ADs.
2) Mantle cell NHL: small lymphocytic lymphoma (SLL) and anaplastic lymphoma

Marto et al [50] described the first case of a 76-year-old woman diagnosed with mantle cell NHL who was also found to have biopsy-proven cutaneous SSc.

William et al [51] reported the first case of a patient with CREST syndrome (calcinosis, Raynaud phenomenon, esophageal dysmotility, sclerodactyly, and telangiectasia) who was subsequently diagnosed with SLL.

In a case report, Bellis et al [52] described a patient with cutaneous limited SSc who was diagnosed with CD30 positive anaplastic lymphoma. The patient received a bone marrow transplantation which resulted in a complete remission of the lymphoma, as well as the disappearance of the sclerodactyly and other signs of SSc.

It has been suggested that chronic stimulation of polyclonal B cells, deficiency of T and NK cells, and the presence of HLA-DR5 genotype might be linked to an increased frequency of lymphomas and other hematological malignancies in patients with SSc [53]. Yet, the development of lymphoma in these case reports can still be incidental.

\section{Multiple myeloma (MM)}

Many studies have reported a potential link between MM and ADs. A large cohort study in the US found that different types of autoimmune entities may trigger the development of MM [54]. A Swedish study that looked at patients diagnosed with $\mathrm{MM}$ and any of 33 different ADs, found an increase in MM standardized incidence ratio in patients with ankylosing spondylitis and scleroderma [55].

Wigley et al [56] reported a case of SSc presenting with SRC in a 68-year-old man with MM who had been treated and had entered remission.

Owlia et al reported a case of a 58-year-old man with a longstanding history of SSc who developed low back pain and visual disturbances and was diagnosed with MM [54, 57].

Although multiple other case reports are available in the literature describing the concurrence of MM and scleroderma [58-60], there are no robust data to show an actual link between these two entities.

\section{$E A C$}

The major risk factor for the development of EAC is Barrett's esophagus (BE) [61]. SSc is associated with an increased risk of BE secondary to chronic acid reflux. Wipff et al [62] studied $50 \mathrm{SSc}$ patients with biopsy-proven BE over a period of 3 years. This study found that the incidence of EAC in the subgroup of patients who have BE with dysplasia was $4 \%$ per year. These findings are in accordance with other available data [63], suggesting an increased risk of EAC in SSc.

Although these results still need to be confirmed by larger cohorts with longer follow-up, the proposed risk suggests the need for close surveillance of SSc patients with BE. 


\section{Cervical and vulvar cancer}

The association of SSc with gynecological malignancies is not well described in the literature.

A cross-sectional analysis conducted recently on a small number of SSc patients found that the incidence of atypical cytological findings on pap smears of SSc patients is higher than in the general population. This finding correlated with antibody Scl-70 positivity.

A Canadian group reported an increased prevalence of abnormal pap smears in 320 women with SSc (25\% versus $13 \%)$, mainly in smokers and those with diffuse SSc subtype [64].

Immunosuppressive therapy used in SSc has been linked to HPV infection. The use of cyclophosphamide was strongly implicated in increasing the risk of HPV and cervical intraepithelial neoplasia (CIN) [65].

A small European study found that only diffuse SSc predisposes to higher frequency of HPV positivity. No difference in prevalence of HPV positivity was noted between limited SSc patients and controls [66].

No specific recommendations are available so far regarding the prevention or treatment of HPV in patients with SSc, but clinicians should be aware of the need to routinely screen for pre-invasive genital lesions before the introduction of biological or immunosuppressive agents.

Clinicians should also ensure that adequate attention is given to cervical cancer screening in women with SSc.

\section{Thyroid cancer}

Most studies regarding the association between SSc and thyroid disorders are of small statistical significance due to limited numbers of patients. A strong link between the two conditions has not been established.

In a cohort study of 769 patients, only two thyroid cancer cases were reported following diagnosis of SSc. The increased relative risk of cancer did not reach statistical significance [63].

Two papillary thyroid cancer cases were reported in a case-control study that included 202 SSc patients, compared to none in the control group [67].

Larger studies on this association are needed. Ultrasound and thyroid function tests probably do not need to be integrated into the workup and follow-up of SSc patients.

\section{Squamous cell carcinoma of the skin}

Squamous cell carcinoma has been reported in association with a rare form of localized scleroderma referred to as pansclerotic morphea. Patients with pansclerotic morphea are found to be at a higher risk for developing squamous cell carcinoma of the skin. A few cases have been reported in the literature of young patients with longstanding pansclerotic morphea developing recurrent squamous cell carcinoma highly refractory to treatment $[68,69]$.

This reported link can be attributed to the interplay of multiple factors such as the presence of chronic skin ulcers, chronic inflammation, scar tissue formation, and the immunosuppressive therapy.

\section{Conclusion}

The data that we reviewed in our paper, although heterogeneous, suggest an increased risk of malignancies associated with SSc. In general, the extensive fibrosis, the effect of the autoantibodies and the use of immunosuppressive drugs (especially cyclophosphamide) have been linked to the higher incidence of cancer in patients with SSc. In particular, organs that are affected by excessive fibrosis, such as the lungs, skin and even the breast, are believed to be at a higher risk. More specific factors have been described, notably prolonged use of CCBs, increased collagen deposition, as well as the hormonal imbalance that were commonly seen in patients with SSc who developed breast cancer. On the other hand, SSc is associated with an increased risk of BE, a major risk factor for EAC, secondary to chronic acid reflux. Furthermore, lymphoproliferative diseases likely secondary to chronic B-cell stimulation, occur in association with SSc.

In conclusion, SSc is associated with an increased risk of cancer, though the evidence behind this association remains weak and contradictory. This raises the importance of questioning whether patients with SSc should be receiving more rigorous cancer surveillance tailored to their disease compared to the general population.

\section{Author Contributions}

All authors certify that they participated sufficiently in the intellectual content, the analysis of data. Each author has reviewed this final version of the manuscript and approves it for publication.

\section{Conflicts of Interest}

The authors declare no conflict of interest relates to this manuscript.

\section{References}

1. Johnson SR. New ACR EULAR guidelines for systemic sclerosis classification. Curr Rheumatol Rep. 2015;17(5):32.

2. Khanna D, Gladue H, Channick R, Chung L, Distler $\mathrm{O}$, Furst DE, Hachulla E, et al. Recommendations for screening and detection of connective tissue disease-associated pulmonary arterial hypertension. Arthritis Rheum. 2013;65(12):3194-3201.

3. Rao V. Scleroderma and Fibrosing Disorders: Advances in Management. Int J Adv Rheumatol. 2010;8.

4. Olesen AB, Svaerke C, Farkas DK, Sorensen HT. Systemic sclerosis and the risk of cancer: a nationwide popula- 
tion-based cohort study. Br J Dermatol. 2010;163(4):800806.

5. Shah AA, Hummers LK, Casciola-Rosen L, Visvanathan K, Rosen A, Wigley FM. Examination of autoantibody status and clinical features associated with cancer risk and cancer-associated scleroderma. Arthritis Rheumatol. 2015;67(4):1053-1061.

6. Wooten M. Systemic sclerosis and malignancy: a review of the literature. South Med J. 2008;101(1):59-62.

7. Onishi A, Sugiyama D, Kumagai S, Morinobu A. Cancer incidence in systemic sclerosis: meta-analysis of population-based cohort studies. Arthritis Rheum. 2013;65(7):1913-1921.

8. Barnes J, Mayes MD. Epidemiology of systemic sclerosis: incidence, prevalence, survival, risk factors, malignancy, and environmental triggers. Curr Opin Rheumatol. 2012;24(2):165-170.

9. Pontifex EK, Hill CL, Roberts-Thomson P. Risk factors for lung cancer in patients with scleroderma: a nested case-control study. Ann Rheum Dis. 2007;66(4):551-553.

10. Shah AA, Rosen A. Cancer and systemic sclerosis: novel insights into pathogenesis and clinical implications. Curr Opin Rheumatol. 2011;23(6):530-535.

11. Trotta F, Potena A, Marchi M, La Corte R, Cavazzini L. Progressive systemic sclerosis and pulmonary malignancy. J Rheumatol. 1982;9(6):970-973.

12. Nikpour M, Hissaria P, Byron J, Sahhar J, Micallef M, Paspaliaris W, Roddy J, et al. Prevalence, correlates and clinical usefulness of antibodies to RNA polymerase III in systemic sclerosis: a cross-sectional analysis of data from an Australian cohort. Arthritis Res Ther. 2011;13(6):R211.

13. Moinzadeh $\mathrm{P}$, Fonseca $\mathrm{C}$, Hellmich $\mathrm{M}$, Shah AA, Chighizola C, Denton CP, Ong VH. Association of anti-RNA polymerase III autoantibodies and cancer in scleroderma. Arthritis Res Ther. 2014;16(1):R53.

14. Shah AA, Rosen A, Hummers L, Wigley F, Casciola-Rosen L. Close temporal relationship between onset of cancer and scleroderma in patients with RNA polymerase I/III antibodies. Arthritis Rheum. 2010;62(9):2787-2795.

15. Saigusa R, Asano Y, Nakamura K, Miura S, Ichimura Y, Takahashi T, Toyama T, et al. Association of anti-RNA polymerase III antibody and malignancy in Japanese patients with systemic sclerosis. J Dermatol. 2015;42(5):524-527.

16. Patterson KA, Roberts-Thomson PJ, Lester S, Tan JA, Hakendorf P, Rischmueller M, Zochling J, et al. Interpretation of an Extended Autoantibody Profile in a Well-Characterized Australian Systemic Sclerosis (Scleroderma) Cohort Using Principal Components Analysis. Arthritis Rheumatol. 2015;67(12):3234-3244.

17. Airo P, Ceribelli A, Cavazzana I, Taraborelli M, Zingarelli S, Franceschini F. Malignancies in Italian patients with systemic sclerosis positive for anti-RNA polymerase III antibodies. J Rheumatol. 2011;38(7):1329-1334.

18. Talar-Williams C, Hijazi YM, Walther MM, Linehan WM, Hallahan CW, Lubensky I, Kerr GS, et al. Cyclophosphamide-induced cystitis and bladder cancer in patients with Wegener granulomatosis. Ann Intern Med. 1996;124(5):477-484.
19. Travis LB, Curtis RE, Glimelius B, Holowaty EJ, Van Leeuwen FE, Lynch CF, Hagenbeek A, et al. Bladder and kidney cancer following cyclophosphamide therapy for non-Hodgkin's lymphoma. J Natl Cancer Inst. 1995;87(7):524-530.

20. Baltus JA, Boersma JW, Hartman AP, Vandenbroucke JP. The occurrence of malignancies in patients with rheumatoid arthritis treated with cyclophosphamide: a controlled retrospective follow-up. Ann Rheum Dis. 1983;42(4):368-373.

21. Tashkin DP, Elashoff R, Clements PJ, Goldin J, Roth MD, Furst DE, Arriola E, et al. Cyclophosphamide versus placebo in scleroderma lung disease. N Engl J Med. 2006;354(25):2655-2666.

22. Gulamhusein A, Pope JE. Squamous cell carcinomas in 2 patients with diffuse scleroderma treated with mycophenolate mofetil. J Rheumatol. 2009;36(2):460-462.

23. Daoussis D, Liossis SN, Yiannopoulos G, Andonopoulos AP. B-cell depletion therapy in systemic sclerosis: experimental rationale and update on clinical evidence. Int $\mathrm{J}$ Rheumatol. 2011;2011:214013.

24. Lafyatis R, O'Hara C, Feghali-Bostwick CA, Matteson E. B cell infiltration in systemic sclerosis-associated interstitial lung disease. Arthritis Rheum. 2007;56(9):31673168.

25. Kuo CF, Luo SF, Yu KH, Chou IJ, Tseng WY, Chang HC, Fang YF, et al. Cancer risk among patients with systemic sclerosis: a nationwide population study in Taiwan. Scand J Rheumatol. 2012;41(1):44-49.

26. Hill CL, Nguyen AM, Roder D, Roberts-Thomson P. Risk of cancer in patients with scleroderma: a population based cohort study. Ann Rheum Dis. 2003;62(8):728-731.

27. Rosenthal AK, McLaughlin JK, Gridley G, Nyren O. Incidence of cancer among patients with systemic sclerosis. Cancer. 1995;76(5):910-914.

28. Chatterjee S, Dombi GW, Severson RK, Mayes MD. Risk of malignancy in scleroderma: a population-based cohort study. Arthritis Rheum. 2005;52(8):2415-2424.

29. Colaci M, Giuggioli D, Sebastiani M, Manfredi A, Vacchi C, Spagnolo P, Cerri S, et al. Lung cancer in scleroderma: results from an Italian rheumatologic center and review of the literature. Autoimmun Rev. 2013;12(3):374-379.

30. Peters-Golden M, Wise RA, Hochberg M, Stevens MB, Wigley FM. Incidence of lung cancer in systemic sclerosis. J Rheumatol. 1985;12(6):1136-1139.

31. Roumm AD, Medsger TA, Jr. Cancer and systemic sclerosis. An epidemiologic study. Arthritis Rheum. 1985;28(12):1336-1340.

32. Kang KY, Yim HW, Kim IJ, Yoon JU, Ju JH, Kim HY, Park SH. Incidence of cancer among patients with systemic sclerosis in Korea: results from a single centre. Scand J Rheumatol. 2009;38(4):299-303.

33. Scope A, Sadetzki S, Sidi Y, Barzilai A, Trau H, Kaufman $\mathrm{B}$, Catane R, et al. Breast cancer and scleroderma. Skinmed. 2006;5(1):18-24.

34. Lu TY, Hill CL, Pontifex EK, Roberts-Thomson PJ. Breast cancer and systemic sclerosis: a clinical description of 21 patients in a population-based cohort study. Rheumatol Int. 2008;28(9):895-899. 
35. Forbes AM, Woodrow JC, Verbov JL, Graham RM. Carcinoma of breast and scleroderma: four further cases and a literature review. Br J Rheumatol. 1989;28(1):65-69.

36. Colaci M, Giuggioli D, Vacchi C, Lumetti F, Iachetta F, Marcheselli L, Federico M, et al. Breast cancer in systemic sclerosis: results of a cross-linkage of an Italian Rheumatologic Center and a population-based Cancer Registry and review of the literature. Autoimmun Rev. 2014;13(2):132-137.

37. Li CI, Malone KE, Weiss NS, Boudreau DM, CushingHaugen KL, Daling JR. Relation between use of antihypertensive medications and risk of breast carcinoma among women ages 65-79 years. Cancer. 2003;98(7):1504-1513.

38. Fitzpatrick AL, Daling JR, Furberg CD, Kronmal RA, Weissfeld JL. Use of calcium channel blockers and breast carcinoma risk in postmenopausal women. Cancer. 1997;80(8):1438-1447.

39. Li CI, Daling JR, Tang MT, Haugen KL, Porter PL, Malone KE. Use of antihypertensive medications and breast cancer risk among women aged 55 to 74 years. JAMA Intern Med. 2013;173(17):1629-1637.

40. Daling JR. Calcium channel blockers and cancer: is an association biologically plausible? Am J Hypertens. 1996;9(7):713-714.

41. Derk CT. Associations of breast cancer development in patients with systemic sclerosis: an exploratory study. Clin Rheumatol. 2007;26(10):1615-1619.

42. Martin LJ, Boyd NF. Mammographic density. Potential mechanisms of breast cancer risk associated with mammographic density: hypotheses based on epidemiological evidence. Breast Cancer Res. 2008;10(1):201.

43. Artlett CM, Rasheed M, Russo-Stieglitz KE, Sawaya $\mathrm{HH}$, Jimenez SA. Influence of prior pregnancies on disease course and cause of death in systemic sclerosis. Ann Rheum Dis. 2002;61(4):346-350.

44. Qian N, Ueno T. Is dysfunction of caveolin-1 a link between systemic sclerosis and breast cancer, opening a window on both etiologies? Arch Med Res. 2010;41(4):297301.

45. Mellemkjaer L, Pfeiffer RM, Engels EA, Gridley G, Wheeler W, Hemminki K, Olsen JH, et al. Autoimmune disease in individuals and close family members and susceptibility to non-Hodgkin's lymphoma. Arthritis Rheum. 2008;58(3):657-666.

46. Anderson LA, Gadalla S, Morton LM, Landgren O, Pfeiffer R, Warren JL, Berndt SI, et al. Population-based study of autoimmune conditions and the risk of specific lymphoid malignancies. Int J Cancer. 2009;125(2):398405.

47. Ekstrom Smedby K, Vajdic CM, Falster M, Engels EA, Martinez-Maza O, Turner J, Hjalgrim H, et al. Autoimmune disorders and risk of non-Hodgkin lymphoma subtypes: a pooled analysis within the InterLymph Consortium. Blood. 2008;111(8):4029-4038.

48. Fallah M, Liu X, Ji J, Forsti A, Sundquist K, Hemminki K. Autoimmune diseases associated with non-Hodgkin lymphoma: a nationwide cohort study. Ann Oncol. 2014;25(10):2025-2030.

49. Smedby KE, Baecklund E, Askling J. Malignant lympho- mas in autoimmunity and inflammation: a review of risks, risk factors, and lymphoma characteristics. Cancer Epidemiol Biomarkers Prev. 2006;15(11):2069-2077.

50. Marto G, Aguiar R, Barcelos A. Mantle cell lymphoma and systemic sclerosis. Acta Reumatol Port. 2014;39(1):8286.

51. William BM, Harbert T, Ganti AK, Bierman PJ. Small lymphocytic lymphoma in a patient with CREST syndrome. Hematol Oncol Stem Cell Ther. 2011;4(3):132135.

52. Bellis R, Frances C, Barete S, Senet P. [Clinical and capillaroscopic regression of CD30 anaplastic lymphoma associated with limited cutaneous systemic sclerosis following autologous bone marrow transplantation]. Ann Dermatol Venereol. 2014;141(6-7):446-451.

53. Sato S, Fujimoto M, Hasegawa M, Takehara K. Altered blood B lymphocyte homeostasis in systemic sclerosis: expanded naive $\mathrm{B}$ cells and diminished but activated memory B cells. Arthritis Rheum. 2004;50(6):1918-1927.

54. Brown LM, Gridley G, Check D, Landgren O. Risk of multiple myeloma and monoclonal gammopathy of undetermined significance among white and black male United States veterans with prior autoimmune, infectious, inflammatory, and allergic disorders. Blood. 2008;111(7):33883394.

55. Hemminki K, Liu X, Forsti A, Ji J, Sundquist J, Sundquist $\mathrm{K}$. Effect of autoimmune diseases on incidence and survival in subsequent multiple myeloma. J Hematol Oncol. 2012;5:59.

56. Wigley F, Friday RP, Shepard JA, Nazarian RM. Case records of the Massachusetts General Hospital. Case 8-2015. A 68-year-old man with multiple myeloma, skin tightness, arthralgias, and edema. N Engl J Med. 2015;372(11):1056-1067.

57. Owlia MB, Distler O, Foratyazdi M, Akhtari M. Visual problem and low back pain as initial manifestation of multiple myeloma complicating pre-existing systemic sclerosis. J Coll Physicians Surg Pak. 2014;24(Suppl 1):S29-31.

58. Colovic M, Jurisic V, Bila J, Colovic N, Palibrk V. FGFR3 and OPG expression in patient with multiple myeloma following systemic sclerosis: case report and review of the literature. Int J Hematol. 2011;93(2):228-231.

59. Gajendra S, Gupta R, Kumar L. Coexistence of scleroderma with multiple myeloma: a rare association. BMJ Case Rep. 2013;2013.

60. Hilal N, Atallah A. Ascites as the presenting symptom of multiple myeloma in a scleroderma patient. Case Rep Rheumatol. 2014;2014:235958.

61. Heath EI, Limburg PJ, Hawk ET, Forastiere AA. Adenocarcinoma of the esophagus: risk factors and prevention. Oncology (Williston Park). 2000;14(4):507-514; discussion 518-520, 522-503.

62. Wipff J, Coriat R, Masciocchi M, Caramaschi P, Derk CT, Hachulla E, Riccieri V, et al. Outcomes of Barrett's oesophagus related to systemic sclerosis: a 3-year EULAR Scleroderma Trials and Research prospective follow-up study. Rheumatology (Oxford). 2011;50(8):1440-1444.

63. Derk CT, Rasheed M, Artlett CM, Jimenez SA. A cohort study of cancer incidence in systemic sclerosis. J Rheu- 
matol. 2006;33(6):1113-1116.

64. Bernatsky S, Hudson M, Pope J, Markland J, Robinson D, Jones N, Docherty P, et al. Reports of abnormal cervical cancer screening tests in systemic sclerosis. Rheumatology (Oxford). 2009;48(2):149-151.

65. Ognenovski VM, Marder W, Somers EC, Johnston CM, Farrehi JG, Selvaggi SM, McCune WJ. Increased incidence of cervical intraepithelial neoplasia in women with systemic lupus erythematosus treated with intravenous cyclophosphamide. J Rheumatol. 2004;31(9):1763-1767.

66. Martin M, Mougin C, Pretet JL, Gil H, Meaux-Ruault N, Puzenat E, Ramanah R, et al. Screening of human pap- illomavirus infection in women with systemic sclerosis. Clin Exp Rheumatol. 2014;32(6 Suppl 86):S-145-148.

67. Antonelli A, Ferri C, Fallahi P, Cazzato M, Ferrari SM, Sebastiani M, Ferrannini E. Clinical and subclinical autoimmune thyroid disorders in systemic sclerosis. Eur $\mathbf{J}$ Endocrinol. 2007;156(4):431-437.

68. Grewal I, Khan O, Davis W. Squamous cell carcinoma and eosinophilia in a long-term course of pansclerotic morphea. BMJ Case Rep. 2014;2014.

69. Durcanska V, Jedlickova H, Slama O, Velecky L, Brezinova E, Vasku V. [Squamous cell carcinoma in localized scleroderma]. Klin Onkol. 2014;27(6):434-437. 